This article was downloaded by:[Australian National University]

On: 2 March 2007

[Australian National University]

Access Details: [subscription number 769293222]

Publisher: Routledge

Informa Ltd Registered in England and Wales Registered Number: 1072954

Registered office: Mortimer House, 37-41 Mortimer Street, London W1T 3J H, UK

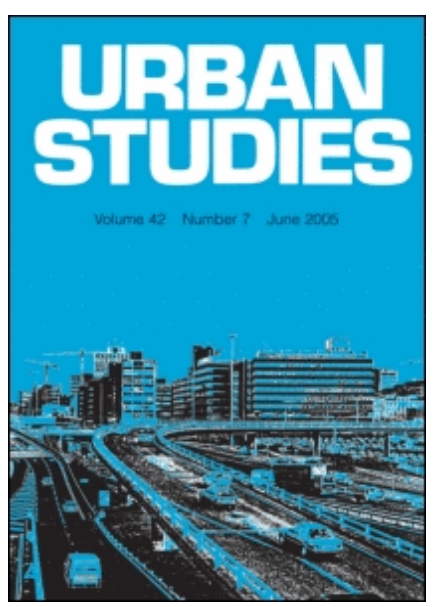

Urban Studies

Publication details, including instructions for authors and subscription information: http://www.informaworld.com/smpp/title content=t713449163 Rethinking urban incivility research: Strangers, bodies and circulations

Timothy Phillips ${ }^{a}$; P hilip S mith ${ }^{b}$

a Research School of Social Sciences, Australian National University. Canberra, ACT 0200. Australia

${ }^{\mathrm{b}}$ Department of Sociology, Yale University. PO Box 208265, New Haven, CT 06520-8265. USA

To link to this article: DOI: $10.1080 / 00420980600676196$

URL: http://dx.doi.org/10.1080/00420980600676196

Full terms and conditions of use: $h$ ttp://www.informaworld.com/terms-and-conditions-of-access.pdf

This article maybe used for research, teaching and private study purposes. Any substantial or systematic reproduction, re-distribution, re-selling, loan or sub-licensing, systematic supply or distribution in any form to anyone is expressly forbidden.

The publisher does not give any warranty express or implied or make any representation that the contents will be complete or accurate or up to date. The accuracy of any instructions, formulae and drug doses should be independently verified with primary sources. The publisher shall not be liable for any loss, actions, claims, proceedings, demand or costs or damages whatsoever or howsoever caused arising directly or indirectly in connection with or arising out of the use of this material.

(c) Taylor and Francis 2007 


\title{
Rethinking Urban Incivility Research: Strangers, Bodies and Circulations
}

\author{
Timothy Phillips and Philip Smith \\ [Paper first received, December 2005; in final form, February 2006]
}

\begin{abstract}
Summary. Research on urban incivility has made progress but has limited scope thanks to a stereotyped and policy-relevant focus on problem neighbourhoods and urban renewal. It also lacks benchmark comparative data, has almost nothing to say about interpersonal incivility and is experiencing diminishing returns to effort. A new agenda is proposed that explores everyday life incivility as this is experienced over the broader population in the course of daily routine. The Everyday Life Incivility in Australia Survey is introduced. This was a random national sample survey collecting systematic narrative information on interpersonal encounters involving a rude stranger. Findings from the study are reported here, documenting the range of low-level incivilities experienced in daily life and outlining some of their properties. The results challenge received wisdom about the corrosive effects of urban incivility on society.
\end{abstract}

How should we think about the problem of incivility in the city? The way most current researchers have answered this question has had profound implications. Their conceptualisation of incivility and its relationship to urban life impacts upon both the direction of their inquiry and the nature of their findings. Incivility has been overwhelmingly imagined as serious, as criminogenic and as the domain of signs of danger. It is represented for the most part as a visual order and as confined to bad neighbourhoods. The threat it poses to social order has been correspondingly magnified. No longer trivial, incivility has been inserted into a discourse of crisis and is taken to be an index of catastrophic civic decline. One need only reflect upon Tony Blair's calls for a society based upon 'respect' replete with an associated imagery of 'sink estates' to understand that incivility is discursively tied to failed social control at the margins. It is argued in this paper that such an approach is flawed and so it takes a radically divergent point of departure. It begins by noting that incivilities can take radically divergent forms and that, although some are associated with crime, with fear and with social deprivation, others are simply part of everyday life and everyday routine. They can take place even among the 'best of people'. In working towards this alternative position, the paper draws from the theoretical tradition that sees the city as the domain of loosely co-ordinated movements and problematic encounters rather than of spaces and boundaries. Derived analogically from Harvey's discovery of the human circulatory system in the early 17 th century, by the mid 
18th century this representation began to be reflected in town planning. Civility and order were tied to the provision of open spaces, boulevards and arcades that facilitated the healthful movement of individuals and prevented the coagulation of unruly crowds (Sennett, 1994). In social theory, this tradition was to be captured in the writings of Georg Simmel, Walter Benjamin and Paul Virilio. From their stance, the fundamental problem for civil society in urban settings relates to the co-ordination of bodies in motion and the management of encounters with those fleeting strangers met en passant. Incivility risks become distributed by the time-space choreography of daily routine, the press of bodies and the rhythm of the streets. The possibility emerges for them to be subjectively and intellectually understood as a routine feature of city life, as an embodied and intersubjective problem to be experienced and managed rather than as a stigmatised and localised phenomenon to be feared and avoided.

This paper maps out where such an approach might take us in the understanding of urban incivility. It begins with a sustained and aggressive analysis of the failings and dead ends of the more conventional approach to minor street-level disorder. In the course of this critique, there emerges a justification and explication of our alternative approach. Next we introduce the Everyday Life Incivility in Australia Survey, indicating how this was informed by a broader and more open theoretical agenda that places strangers, bodies and circulations at the core of urban life. Finally, results from the study are presented, these validating our broader approach and confirming that the dominant paradigm for thinking incivility is incomplete and inadequate.

\section{Current Incivility Research: A Review and Critique}

The social sciences are often derided for their inability to generate consensus and are characterised as an arena where fruitless wars of position between conceptually disparate world-views produce manifestos rather than core knowledge. Such sweeping denunciations often neglect the productive work that goes on within sub-fields, the way nodes of inquiry develop that move forward with a cautious but relentless momentum. Consider the past 15 or so years of effort researching urban incivility. Following earlier trailblazing but somewhat speculative work from agendasetting scholars like Jane Jacobs (1961) and James Q. Wilson (1975), this domain of inquiry has now stabilised into what Thomas Kuhn called a 'normal science'. Scholars can agree on what the core issues are in the study of urban incivility, share research protocols and endorse repeatedly validated findings. There is even concord over the methodological problems that currently beset work within this literature that walks the line between neo-positivist criminology and the policy-relevant wing of the new urbanism. Yet such an achievement does not come without its costs, for a way of seeing is also a way of not seeing. If some issues are identified and researched exhaustively, others must be left unexplored. Or put another way, the greater the magnification the less the field of vision. But we are getting ahead of ourselves. Before moving on towards our critique of this literature it is worthwhile to review quickly its contours.

The core problem of the normal science of urban incivility research is the relationship of minor indiscretions and signs of disorder to crime and fear of crime, to neighbourhood levels of economic and social capital and to quality of life (Taylor, 2000). The original impetus for research was the discovery from early crime victimisation surveys in the 1970s that fear of crime seemed to outstrip actual crime experiences. Perceptions of the unruly street and of rampant urban decay were thought to be responsible for this distorted impression (Wilson, 1975). This rough-and-ready hypothesis about mental process was soon firmed up into a vision where outcomes could be serious in scope and structural and behavioural in quality and not simply modifications to subjectivity. The canonical formulation of this 'broken 
windows' criminology is that seemingly trivial minor indiscretions if prevalent enough can have significant implications down the line for personal and collective wellbeing (Wilson and Kelling, 1982). They operate as a specifically visual semiotic system that signals decline and danger, generates negative perceptions of place, suggests that street-level informal social control is weak and so drives away upstanding or socially and economically mobile citizens. At the same time, this visible disorder attracts various more serious criminal activities and neighbourhood crime rates increase. The result is a spiral of decline in which the watchful eyes of potential guardians are averted and serious offenders move in, aware that the risks to apprehension are lower than elsewhere. Signs of disorder multiply and those guardians who can afford to do so abandon ship. Validating this hypothesis that explains simultaneously outcomes as diverse as perceptions, crime rates and neighbourhood decline has become the Holy Grail of incivility research. Too difficult and complex to be explored in its entirety, researchers have usually contented themselves by looking at one or two of its propositions. For example, that incivility correlates with crime perceptions, or that neighbourhood decline and inequalities between neighbourhoods are accelerated by incivil activity (Skogan, 1990).

The core research protocols revolve around interlocking various datasets. These include the use of census and other data to map the socio-demographic characteristics of neighbourhoods; the deployment of observational protocols that permit the objective coding of neighbourhood characteristics such as vacant lots, graffiti or loitering; the retrieval of official crime data from places such as police records; and the administration of surveys tapping into experiences of victimisation, fear of crime and perceptions of neighbourhood quality. Next, correlations are sought and inferences drawn.

The repeatedly validated findings of the field tend to be about perceptions and are unremarkable. As might be expected, it is established that perceived incivilities have reasonably strong correlations with fear of crime in general and fear for personal safety in particular (Rountree and Land, 1996). Likewise — and equally unsurprising perceived incivilities correlate well with the perceived prevalence of crime (Perkins et al., 1992). There are also studies running in the predicted direction showing that perceptions of incivility in an area correlate with the true crime rate (Taylor, 2000, p. 78) - a result that would seem to suggest that people are sensible enough to know when they live in a bad area. Causal ties of real (not perceived) incivility to real (not perceived) 'serious' crime and documented or independently assessed neighbourhood decline have proved somewhat more elusive. Perhaps this is due to the methodological challenges (see below), for one commentator recently remarked that

to date we have no longitudinal tests of the independent contributions of incivilities to neighbourhood changes in fear, crime, or structure (Taylor, 2000, p. 83; see also Sampson et al., 2002, for a similar assessment).

Existing cross-sectional data suggest that, even if such research is conducted, it is likely that incivilities will have only modest effects after control variables for crime and neighbourhood structure are introduced. In general, the literature to date provides results consistent with but not conclusive for the core hypothesis (Robinson et al., 2003).

The core methodological problem that everyone seems to agree upon centres upon the need for longitudinal data to demonstrate causal effects (Taylor, 2000). ${ }^{1}$ In general, the literature has done a good job in showing that results run in the expected direction in cross-sectional designs, especially where perceptions are concerned, but has done less well in proving that real and perceived incivilities have enduring, independent impacts on subsequent levels of crime, disorder and neighbourhood decline (Sampson et al., 2002). With systematic experimentation likely to be ruled out by ethics committees and strong lag effects anticipated, what is needed is an 
expensive project that repeatedly and regularly measures real and perceived incivility over a period of years and then correlates this with outcome variables. Relatedly, there is the matter of disentangling indicators of disorder from indicators of crime or neighbourhood disorganisation such that their independent effects can be partialled out in statistical analysis. Discarded drug needles could be counted by observers and used as a sign of disorder. Yet they are also an indicator of the real crime of drug use, a strong index or 'natural sign' of illegal drug dealing, and probably correlate closely to the residential composition of the neighbourhood. Unsupervised groups of teenagers have been used as an indicator of both social disorganisation and incivility, raising the question whether incivility is simply visible disorganisation (Taylor, 2000, p. 83). Further, it is generally concurred that there is the need to disaggregate the concept of 'fear of crime' to include more affect-neutral perceptions of risk and also to separate out altruistic fears for significant others or the community at large.

The relatively dense nexus of publication and investigation around these themes is a significant achievement for contemporary urban criminology and not one that we intend to deride or mock. Nevertheless, we argue that like all normal science the consensual activity of filling in the blanks leaves an increasingly restricted intellectual vision as the cycle of academic production unfolds. In this case, the routinisation (and arguably capture) of ivory tower inquiry has been accelerated by research protocols, programmes and proposals that attempt to tap into one of the more bountiful current applied social science funding streams. These usually involve collaboration with local and city governments (so-called research partnerships) as well as funds from national organisations that allocate priority to the solution of front-burner social problems. The resulting search for a policy magic bullet has been a tight and professional one. Yet it lacks the explorer's zeal. In the quest for funding and policy legitimacy, intellectual isomorphism sets in. Research proposals start to clone one another seemingly in a 'cut and paste' operation, item banks replicate, the citation pattern sees nothing valid written before 1980. The field looks increasingly to narrow middle-range criminological theory for inspiration rather than to the broader, less intensively cultivated pastures of classical social theory or the more intellectually diverse agendas of contemporary cultural theory.

To sum up crudely, incivility research has become a sub-field of applied criminology oriented towards a 'social problem' that has disconnected itself from the wider sociological tradition and the intellectual opportunities this brings. Today, we argue that the costs of this movement have begun to outweigh the benefits. For the sake of clarity, it is perhaps useful to innumerate these costs here and to formulate an alternative and somewhat broader vision of what urban incivility research could look like.

(1) More and more research effort is spent hunting down elusive causal links. However, as Robert Sampson and his colleagues point out the "evidence is not as strong as broken windows theory would suggest" (Sampson et al., 2002, p. 465). A recent and very comprehensive and expensive study by Sampson himself along with Stephen W. Raudenbush (1999) found no real support for the causal impact of incivilities. It is now reasonable to assume that, if located, these are likely to have unspectacular effects relative to the usual and more intractable (i.e. expensive to fix) suspects such as the demographic composition of an area, the unemployment rate or household stability. Panning through tailings of the normal science in this way will bring a little gold dust but no El Dorado. The time has come to be more imaginative and to cast around for new and more easily profitable veins for inquiry where the law of diminishing returns does not impose such a heavy tax on time and energy.

(2) In the dominant paradigm, incivility is defined and researched in a restricted and stereotyped way as the activity of marginal and undesirable people who might be perceived as threatening or as trouble-makersfor example, groups of youths hanging out, 
graffiti artists and squeegee bandits. Attention is also given to the visible signs of urban decay. Such an approach ignores incivilities perpetrated by or indeed likely to be experienced by the wider community. In effect, research systematically discriminates against both the middle classes by marginalising them in the research protocol, and against the poorer or unconventional sections of the community through perpetuating the binaries that imaginatively separate the 'unruly' from the 'respectable'. Further, without efforts at benchmarking, we have no idea what might be especially interesting about the subset of incivilities and perpetrators that is currently being investigated. For example, what are the specific qualities of those urban incivilities that generate 'fear'? How do graffiti or broken windows differ in their effects from the total pool of incivilities we might have in daily life?

(3) The perception of the city in conventional research is also problematic. First, it is imagined as a series of residential 'neighbourhoods' or 'blocks' of dubious quality. Those most likely to be scrutinised and considered worthy of research interest seem to conform to an image of the kind found in video games like the recent immensely popular 'Grand Theft Auto: San Andreas', with graffiti-covered vacant lots, boarded-up shops and sidewalks populated by White trash, Black gangs, home boys, tattooed punks, drug dealers, prostitutes, thugs and lurkers. Granted, such places exist. However, they are by no means typical of the urban environment experienced on a daily basis by many people. Indeed, for the most part, the middle classes simply avoid such spaces, while even their teenage sons visit them only courtesy of the virtual reality of PlayStation 2. There is a pressing need to open up the investigation of incivility to encompass the city as a whole, including the affluent and leafy suburbs, the air-conditioned shopping malls and the chattering grounds of café society.

(4) Relatedly, the city is imagined in the mainstream criminological/urban policy literature on incivility as discrete spacestypically, as we just mentioned, densely populated residential 'neighbourhoods' or blocks' near the city centre. These are typically compared and contrasted to each other. This is a dated, static ecological conception that is seriously out of touch with contemporary trends in urban sociology and theory speaking of the 'exopolis', the 'edge city', the 'world city', the 'consumption city', the 'hedonistic city', of 'flows', 'networks' and so forth. It is a curious vision formulated around the rather problematic belief that where people sleep is the pivotal factor shaping their experience of the city, their imagined geographical identity and the morphology of urban form. The rise of this operational collective representation has no doubt been boosted by the availability of census data, the routine GIS mapping of crime data by law enforcement agencies and potentials for the relatively easy unobtrusive observation and coding measurement of residential or mixed-use block characteristics. The problem is that we have very little information about the distribution of incivilities over the range of urban locales other than the residential. How do spaces used for transport, work, leisure or consumption influence exposure to incivilities and responses to these? What about privately owned public spaces like malls and airports? Many events of interest to the study of incivility take place outside the 'neighbourhood'. We know almost nothing about these. Recent efforts to look at the role of subjective mental maps of neighbourhoods or other-neighbourhood activity (such as buying or using drugs somewhere other than where you live; see Sampson et al., 2002) in our view do not go far enough as a critique of the residential paradigm as it stands.

(5) Why not? Put simply the static conception of the city as residential spaces cannot be fixed by looking at such interneighbourhood or multiple-neighbourhood process because the paradigm ignores what happens during the movement or flow between locales. Since the writings of Walter Benjamin (1997), a vision of the town and city has been available to social science that imagines it as a web through which 
humans move along vectors between nodes, these being related to home, labour, education, pleasure and consumption. Paul Virilio's (1986) work elaborates on this tradition with his insistence that the management of speed or 'dromology' is a fundamental quality of, and problem for, the organisation of urban life. Such a conception animates the city in the manner of the celebrated film Koyaanisqatsi (Reggio, 1983) which uses time-lapse and fast-forward photography and long perspective shots to show the operation of the city to be one of structured speed, an environment involving the circulation of people and machines in patterned activity. This paradigm shift towards the model of the city as interconnecting reticulations brings to our attention the fundamental problems of movement co-ordination and also those spaces that attempt to resolve this problem. We mean here the locales where movement is conducted or facilitated-train platforms, sidewalks, parking lots and so forth. Competition for movement spaces, divergent speeds and urgencies, encumbered movement and crowded spaces are all possible generators of incivil, embodied collisions in this environment of structured and usually consensual fluidity (Fischer, 1999).

(6) Likewise, the concept of the incivility itself needs to be opened up. Although early theoretical tracts on incivility such as Wilson's make mention of interpersonal confrontations with squeegee bandits, 'heyhoney' hassles and so forth, these have been all but forgotten in the new orthodoxy. Present research has an overwhelming focus on physical or environmental incivilities such as graffiti, garbage and decay. These are static, material and inscribed on the urban fabric. This restricted focus has arisen largely because such traces are amenable to unobtrusive measurement by trained coders armed with clipboards. For methodological reasons, interpersonal incivilities - the direct encounters with the rude Other that we all probably wish to avoid more than a wall of graffiti-have dropped out of the frame. These differ from physical incivilities not only because they involve subject-on-subject encounters, but also because they are processual and evolve through sequences of interaction. Efforts to capture such interpersonal, embodied dynamics through unobtrusive means are usually feeble. Groups of young people hanging out on the block can sometimes be observed through the windows of a cruising SUV in drive-by research, as can the occasional street-corner prostitute or door-step drunk. ${ }^{2}$ Yet activities like queue jumping, dirty looks and verbal harassment pass unnoticed or are recorded so infrequently as to be useless for statistical purposes. Further, goings on in those enclosed public spaces associated with circulation and consumption (shopping malls, airports, rail stations) cannot be detected from an exterior block survey - and besides, such spaces (like parks and plazas, too) do not readily conform to the protocols developed for block coding. Something needs to be done to bring social interaction back into the study of incivility and to open up the investigation of interpersonal activities and encounters that are perceived in negative ways. Just as there is a powerful theoretical mandate for reimagining the city, there is one authorising this shift back to interpersonal interaction. It lies in the tradition of work on the Stranger that extends back to Simmel (1997) and forward through Goffman (Fine and Smith, 2000) to Bauman (2005), indicating the challenges that co-presence with others presents, particularly in urban settings.

(7) The impacts of incivility are represented and measured in an equally unimaginative way. The dominant assumption is that incivilities generate 'fear' and that fear drives good citizens away from marginal areas. This seemingly stems from the stereotyped urban paranoia that animates the imagined subject of the new urbanism. It is reinforced by the availability of off-the-peg 'fear of crime' measures in crime victimisation and general social surveys that allow for replication and which are consistent with the 'social problem' fund-seeking orientation of contemporary research. As we have argued elsewhere (Smith and Phillips, 2004), possibilities for alternative emotional responses that 
are well mooted in the social theory literature-anger, indifference, amusement, disgust - are never really explored or offered to respondents. Moreover, 'fear' is measured using hypotheticals and, once again, these are usually focused on the 'neighbourhood' not the wider urban experience (for example, 'How safe do you feel walking round your neighbourhood at night?'-not 'How safe do you feel in the shopping mall?'). Likewise, responses to incivility other than situational withdrawal have barely been investigated. Might we not 'continue as before' after our brush with disorder, or even seek out the thrill of the unruly and unpredictable, as epitomised by the nightly ratissage through local places carried out by the élite residents of the gated community 'Eden-Olympia' at the centre of J. G. Ballard's recent prescient novel, Super-Cannes (2001)?

Our position, then, is that research on incivility is becoming crippled by policy relevance. It operates with a restricted and stereotyped pool of incivilities and perpetrators and a static concept of the city as a series of spaces where people reside. Thanks to funding strictures, the need to mesh databases and the partly reasonable but partly simply robotic replication of standard criminological modules, it is a discourse that is moving in ever-diminishing circles as it hunts down small effect after small effect. We suggest that there is a pressing need for research which explores the full range of incivilities without pre-judging where or with whom a 'social problem' lies, what an incivility is or what the emotional or behavioural response will be. This needs to engage with an understanding of the city as a zone of movements between a diversity of locales (only one of which is the residential neighbourhood) in which agents with bodies make use of movement corridors and technologies. The interpersonal and interactional qualities of incivil encounters with an Other also need to be brought back into the analytical frame. In short, let's put the microscope labouriously constructed by contemporary urbanist criminology back in its box and pull out the Panavision camera that can give us a bigger, moving, full colour picture. In this paper, we introduce one alternative strategy for accomplishing this task and provide an assay of its utility.

\section{Introducing ELIAS: The Everyday Life Incivility in Australia Survey}

Funded by the Australian Research Council, we report here on a research project which attempts to push incivility research in the broader direction we have just proposed. Operating under the acronym ELIAS (Everyday Life Incivilities-an Australia Survey) (Phillips and Smith, 2005), the study was concerned with designing a new cross-sectional survey dedicated to the topic of embodied commonplace stranger incivility arising from routine activities; this was then administered to a large representative sample of Australians. Here, we describe some key methodological features which distinguish the project from the normal science research in the field, before going on to illustrate some of the ways in which these qualities help us to clarify and renew extant understandings of incivility in social science research.

\section{Research Design}

A preliminary sequence of filter questions ascertained whether or not the participant could recall a personal experience of an incivil event within the space of the past month. Participants who were able to retrieve such an event were then taken by the interviewer straight to the start of the first section of the survey. Where more than one event was recalled, the interviewer asked the respondent to concentrate their mind on the most recent occasion. In this first part of the survey, a key aim was to ask a series of precise questions that would enable us to document in fine detail the respondent's selfreported account of 'what happened'. To this end, the survey tool needed two key attributes. First, it was important that it be broadly based, enabling us to accommodate in our coding frames the sheer variety of different kinds of incivil events and their component 
characteristics - and not just the limited pool of current interest to criminology (Phillips and Smith 2003; Smith and Phillips 2004; Phillips, 2006). Secondly, the instrument had to be capable of capturing the varying depth and complexity of incivil events. While some may constitute a literal 'one act play' (Ives, 1995), others take place over a number of (sometimes escalating) scenes (Bateson, 1973). Consequently, a narrative approach was used to facilitate recall. This involved the interviewer asking questions about the details of the event step-by-step and enabling the respondent to connect the parts of their story along the lines of a familiar linear sequence. It has long been suggested that the individual is prone to think about and remember such events in narrative form (Carlyle, 1855/2003). In effect, what we achieved here was the systematic coding of a first-person narrative in the process of data collection.

In the prior section of this paper, we indicated some omissions and deficiencies of existing research. In retrieving data on the narrative of and context surrounding the incivil encounter, we were careful to include items addressing these themes. We note first that any event perceived by the respondent as involving an incivil stranger was included in the survey and not only those conforming to a 'broken windows' stereotype or researcher definition. Moreover, respondents were able to tell us about this most recent event wherever it took place, not only to relate those that happened in dubious locations of specific policy interest. The event location was coded without reference to neighbourhood names, block numbers or postcodes as is standard practice. Instead, we coded the event against a number of commonplace meaningful environments for encountering the rude stranger in routine daily life outside the home: the street, the shopping mall, the cinema, the sidewalk, the bus, the bar, the car park and so forth. These are functional spaces where strangers move and mix, not residential quarters. As we were also interested in the distribution of incivilities around the entire city, a further set of items asked whether the event took place in the $\mathrm{CBD}$, inner city, outer city and so forth. We did not give analytical priority to the deprived inner-city suburbs and so exclude benchmarking opportunities. Themes of movement were also addressed by asking whether the respondent was on foot, in a car or on public transport. We also inquired what they were doing and where they were going, whether their movement was encumbered by baggage or a social responsibility and if they were going faster or slower than others at the time of the incident. In short, we were far more interested in where they were and what they were doing and how they were moving, than in the address of their bed. Because respondents were reporting events directly to us, we were able to tap into the vast range of low-key, low-visibility, non-criminal embodied incivilities that have eluded conventional incivility research. We were able to code bumps and knocks, queue-jumping, insults and dirty looks for example. These are the kinds of event that occur relatively frequently in daily life, but that simply cannot be detected using drive-by and clipboard social science. Finally, respondents were asked about their emotional and behavioural responses to the incivility at various points during and after the encounter. Again, we did not assume fear or avoidance would eventuate, but rather were able to code possibilities like rage or disgust, remonstration or revenge and, perhaps most important of all, indifference. Although not addressed in this paper, we can add that the characteristics of the rude stranger were also coded without prejudice. We probed not only for age, gender and race, but also asked if the offender looked 'rough or respectable'. Our earlier research had suggested that offenders and victims were socially similar (a finding, incidentally, that is consistent with routine activities criminology). Being open in this way allowed us to capture better the diversity of the incivil strangers and avoid a stereotyped and restricted focus on marginal youth, petty criminals and the homeless that simply does not capture middle-class experience. 
The second section of the survey was completed by all participants and can be dealt with more briefly. For the respondents without an incivil event from the previous month to report, it was their entry-point into the substance of the survey. For those who had just provided a fine-grained recounting of the particularities of a recent personal experience of a specific incivil event, the second part of the survey represented a change of tack. This part of the survey stepped back from the narrative specifics of a concrete event and shifted onto more general and diffuse terrain. It included modules on attitudes to incivility in general, personal levels of trust and social capital, everyday routine and so forth as well as a range of socio-demographic variables. The idea here was to tap into items that the literature suggested were relevant as background causes, consequences or contexts of everyday life incivility.

\section{Data Collection}

Between 26 June and 9 August 2005, the ELIAS survey was administered to $N=1621$ adults (defined as people over the age of 18) throughout Australia using computer-assisted telephone interviewing (CATI). Recruitment proceeded by way of stratified systematic random sampling. In using this sampling procedure, we sought to give all individuals within the scope of the sampling frame (electronic white pages residential telephone directory for Australia) an equal chance of being selected, as well as endeavouring to match the distribution of sub-groups along the criteria of age, gender and state of residence with parameters drawn from the national census (ABS, 2002). Once drawn from the white pages, each sampled household was sent an initial letter about the project. This letter introduced the project and foreshadowed the possibility that the recipient may be phoned in the next month or so and invited to participate in the study. To this end, the letter asked them to keep a mental note of any incivil events they happen to experience in the interim.
The response rate, defined as contacted participants who agreed as a proportion of those who agreed and refused combined, was 30 per cent. This figure is not overhigh in light of textbook ideals from a few years ago documenting the response rate social researchers should be aspiring for when collecting data by telephone interviewing (Weisberg et al., 1996). Yet, it is perhaps unsurprising, under conditions of a rapidly proliferating and largely unregulated telemarketing industry (in a broader context of declining fixed-line subscriptions and growing mobile phone service usage), that respondent recruitment becomes more difficult for academic survey researchers using CATI (ACMA, 2005; Richardson and Weill, 1999). The result has been the emergence of a broader culture of public suspicion towards unsolicited calls to home phones and lower levels of preparedness to comply with the requests of uninvited callers, or even to take the call at all when filtering technologies such as caller number display, texting-in-advance and voice message services (i.e. Telstra 101) are routinely available. Bret Easton Ellis' recently stated preference for an "unlisted outgoing-only phone line" (2005, p. 21) may be a sign of things to come. This said, the response rate is similar to that achieved by the Australian Bureau of Statistics in its own phone survey research. Our confidence in the robustness of our findings was further boosted by their concordance with those from our earlier, independently selected focus groups and from overseas policy research on commonplace incivility such as that of Public Agenda (Phillips and Smith, 2003; Smith and Phillips, 2004; Public Agenda, 2003).

The telephone interviews lasted on average 29 minutes. There was, however, a considerable range, reflecting the frequent usage of filter questions within the internal structure of the survey instrument. The interview could be over within 15 minutes for the respondent reporting no experience of an incivil event within the past month at the commencement of the survey. Yet, at the other end of the range, events with a long and complex sequence of sub-parts triggered 
the introduction of corresponding submodules. In seeking to capture empirically the full depth and breadth of this kind of more complicated event, interviews on occasion went beyond 45 minutes.

\section{What Is Incivility? The Importance of Definition}

As we have alluded, a distinguishing feature of the current project was an interest in the routine, fleeting, embodied interpersonal incivilities in public spaces that are not currently captured in criminological research. However, we also wished to allow participants to identify what they themselves thought was incivil rather than starting out by imposing our own researcher-derived definitions upon them. Hence the following 'event recall' question at the commencement of the survey.

Now, can you think of an occasion within the past month when you came across a rude stranger. Can you recall such an event? We're looking in particular at events that occurred in Australia, that involved another person you'd never seen or met before, just another member of the general public (rather than someone at their work), someone you came across in the course of simply going about your everyday life activities (rather than connected with your work).

This general opening statement allowed the respondent to decide what was rude but at the same time allowed us to eliminate incivil events that did not involve an interpersonal encounter with a rude stranger-for example, rude behaviour seen on television, observation of graffiti from a train window, noisy neighbours. We were able to check carefully whether any nominated event qualified for inclusion in our category of interest by asking the respondent, one at a time, five eligibility questions related to this statement (see Table 1). If the recalled event failed on any criteria, the respondent would cycle through the filter questions until an eligible event was nominated. Under conditions where an eligible event was unable to be
Table 1. Set of questions and corresponding eligible answers required for a recalled event to qualify for inclusion in the study as a case of everyday life incivility $(N=1621)$

I'd like to ask you about the most recent occasion when you came across a rude stranger. How long ago did this event happen? (Not 'over one month ago')

Did this event happen in Australia? (Yes, happened in Australia)

Was the rude stranger completely unfamiliar to you, that is a person you had never seen or met before? (Yes, complete stranger)

Was the rude person just another member of the general public, or were they working in a job at the time? (Yes, just another member of the general public)

Now, how about you, were you working in a job at the time? (No)

Source: ELIAS (2005).

proffered, the respondent skipped Section A of the survey and went straight through to Section B, the general questions within the survey that were completed by all respondents.

The first question stipulated that the event recalled by the respondent needed to have happened within the previous month. Due to the relatively higher frequency and lower cost of individual exposure to everyday-life incivil events in contrast to criminal acts, we believed that it would be difficult for people to remember clearly details of time-distant trivial episodes. For this reason, we worked with a maximum recall period of just one month, rather than the 12 months that are more common in the contemporary crime victimisation survey (Cantor and Lynch, 2000). Question 2 simply worked to ensure that the focus fell squarely on incivil events that manifested within a particular social and cultural context-in this case, Australia. An incivil event reported by an Australian while they were on holiday in another country, say the USA or Indonesia, did not qualify. In this way, outliers and complexities could be avoided. 
The next two questions were designed to ascertain that within the incivil event the 'rude stranger' was in fact a pure stranger to our respondent, this being the archetypal theoretical category associated with public life in the city (Bauman, 2003). To do this we sought to rule out events involving three common types of 'familiar strangers'; the first kind we have 'seen before' but we know not 'what they do' (for example, the nondescript person I see on the late night train every Tuesday, but never speak to); the second sort we have never 'seen before' but know 'what they do' (for example, the uniformed crossing guard I encountered for the first time at the lights while driving to work one day); and the third type we have both 'seen before' and know 'what they do' (for example, that security guard who always stands outside the front of the local supermarket around closing time). These three types all involve strangers who are to some degree known and knowable rather than fully unpredictable or ambiguous. The final filter question was designed to ensure that the event was not one where the respondent was not acted upon by the 'rude stranger' whilst occupying a visible social role or job (for example, "I was working as a bank teller and got abused by a customer tired of queuing").

Table 2 shows that around one-third of our respondents reported having experienced an everyday life incivility that met these fairly restrictive criteria in the prior month. Of interest, these participants on average reported that the incivil event they experienced had occurred between one and two weeks (median response category) prior to them participating in the telephone survey. This finding augments our confidence that most of our respondents would have clear recall and were not recounting some vaguely remembered event from several weeks prior that they now claimed had happened 'around a month ago'.

\section{Incivility: Narrative and Meaning}

The first major section of the survey is distinguished by its emphasis upon narrative and
Table 2. Preliminary sequence of iterative filter questions: key frequency distributions $(N=1621)$

\begin{tabular}{lrr}
\hline & Percentage & $N$ \\
\hline $\begin{array}{l}\text { Whether respondent } \\
\text { could recall an event } \\
\text { within the past month }\end{array}$ & & \\
that qualified as an & & \\
everyday life & & \\
$\quad$ incivility & & \\
Yes & 31.3 & 508 \\
No & 68.7 & 1113 \\
Total & 100.0 & 1621 \\
Length of time ago (in & & \\
$\quad$ advance of day of & & \\
telephone interview) & & \\
that nominated event & & \\
$\quad$ was reported to have & & \\
happened & & \\
Today & 8.7 & 44 \\
Yesterday & 8.3 & 42 \\
Two to three days ago & 11.4 & 58 \\
Four to six days ago & 6.1 & 31 \\
Up to a week ago & 15.2 & 77 \\
One to two weeks ago & 12.4 & 63 \\
Two to three weeks ago & 24.8 & 126 \\
Three weeks to one & 13.2 & 67 \\
$\quad$ month ago & & \\
Total & 100.0 & 508 \\
\hline
\end{tabular}

Source: ELIAS (2005).

meaning as ways of approaching incivility research in the social sciences. To reiterate, we sought in designing this research study to go beyond two serious weaknesses of crime victim survey: their focus on the quantity of victimisation (how many times) rather than the quality (dynamics, process) of an event (Zedner, 2002); and their associated propensity to neglect the ways in which the citizens' understandings of what is incivil, unruly or objectionable might depart from official and criminological definitions (Duncan, 1996). Table 3 reports the cross-section of everyday incivilities named and experienced as such by the 508 respondents who recalled experiencing such an occasion in the prior month. It also documents the regularity with which each type was nominated and in so doing provides strong evidence for the validity of a perspective that places bodies and movements centre stage. By far the most commonly 
Table 3. Frequency distribution: range of 'everyday incivilities' reported by respondents and the regularity with which each was nominated as such $(N=508)$

Question: Now, what did the stranger do in the very

first instance that made you think of them as rude ...

What exactly did they do?

Percentage $\quad N$

(1) Movement

(i) Bumped into me

$9.4 \quad 55$

(ii) Blocked my way

$9.6 \quad 56$

(iii) Pushed in front of me (cut me off)

25.3

(iv) Tailed me

$3.6 \quad 21$

(v) Stopped abruptly in front of me

(vi) Took up too much personal space (seating)

(vii) Invaded my personal space

1.9

1.4

5.1

8

(viii) Swerved in front of me (child)

3.8

(ix) Sat or stood in front of me (cinema)

1.2

30

Sub-total

61.2

(2) Bodily Management and Display

(i) Spat

(ii) Bodily gesture (dirty or lewd look, the ups)

(iii) Waste disposal (fag end, takeaway food packaging)

(iv) Acting in poor taste (reading porn on train)

11.5

0.7

1.4

358

Sub-total

13.9

2

(3) Sounds

(i) Mobile phone (loud ringing, irritating ring tone)

$0.2 \quad 1$

(ii) Motor vehicle (beeping horn, revving engine)

3.2

(iii) Loud talking (in cinema)

1.4

8

(iv) Screaming, screeching or shouting (child)

5.6

33

Sub-total

10.4

61

(4) Language

(i) Swearing

(ii) Sexual remarks

(iii) Prejudicial comments (racist, sexist)

11.3

0.9

2.2

0.2

(iv) Non-English language

14.6

66

Sub-total

100.0

585

Note: 122 incivilities were coded as 'other'.

Source: ELIAS (2005).

mentioned form of incivility was movementrelated (61.2 per cent). Within the subcategories of this type, being "pushed in front of' or 'cut off' was recalled most frequently ( 25.3 per cent), followed by 'having one's way blocked' (9.6 per cent) and 'being bumped into' (9.4 per cent). The other three general modalities of incivility related respectively to language (14.6 per cent), bodily management and display (13.9 per cent) and sound (10.4 per cent). Within the sub-categories for each of these last three types, one particular manifestation of incivility stood out as dominant: gestures such as 'dirty or lewd looks', or 'the ups' (11.5 per cent, bodily management and display), 'swearing' (11.3 per cent, language) and 'screaming, screeching or shouting' (5.6 per cent, sound), the latter a kind of incivility commonly associated in public places with a marauding child under the guardianship of the non-interventionist parent (Davis, 1991). 
The ELIAS project was distinguished by a dedicated interest in treating everyday life incivility as a sequence of stranger-onstranger interaction amenable to narrative recall. Hence, we diverged from the convention within crime victimisation surveys to document whether or not the participant has been victim of a laundry list of crimes and instead focused in depth on just one memorable encounter event in the mind of the respondent. We wanted to record the discrete 'episodes' within the larger 'production' of these events, treating them as unfolding interaction sequences. In effect, we have not a sample of individuals, but rather what Randall Collins (2000) has claimed is much needed in social science-a sample of 'situations', these being the atoms of social life. Of particular concern was the flow of individual action and interpretation that might 'power-up' these events, emotionally energising their participants to keep them going rather than bring them to a stop (Bateson, 1973; Collins, 1988).

Table 4 shows the progress of the stories participants told us about their recent experience of everyday life incivility and thereby captures the diversity of incivil encounters. We can begin with events that 'started up', of which the total pool as reported in Table 2 was 508. In many cases, nothing further happened. Indeed, sometimes the respondent was simply engaging in 'unobtrusive observance' (Emmison and Smith, 2000) as a spectator of an everyday incivility. They 'made note' of the event, but there were no subsequent interactions or relations with the rude stranger.

About one in three progressed into what we referred to as events with intermediate episodes. To move into this episode phase, the respondent had to have 'said or done something back to the rude stranger' after experiencing or witnessing the initial incivility. About one in three respondents took this step (35.2 per cent). While that was the end of the matter for a little over half of the respondents who decided to enact some kind of remonstrative response, the remainder of the events continued on (15.2 per cent of original pool), with 'the rude stranger then going on to do or say something in reply' in 77 cases. At this point, the meeting of strangers concluded for about three in four of these remaining respondents. However, for the rest of these participants left at this point (3.9 per cent of original pool), the situation continued on to generate what we referred to as events with big finales. In these 20 cases, our respondents reported the potentially risky or embarrassing circumstance of further engaging with the rude stranger with respect to the matter at hand. ${ }^{3}$

One of the main strengths of a narrative approach to studying incivility in the social sciences is that it provides us with a way of methodologically finding out more about the types of incivil situations that will tend to escalate once they have been perceived as such by the individual, entering what Bateson (1973) refers to as a process of 'schismogenesis', as against those kinds that are registered but exhibit a response that privileges what Norbert Elias (1987) has termed 'detachment' over 'involvement'. We can illustrate something of the power of this approach by mapping out here the relative likelihood that particular originating incivilities will lead to escalation or otherwise.

Table 5 shows that the four general types of incivility varied little in their power to propel the victim out of the state of the 'unobtrusive observer', an ontological and existential condition reminiscent of Baudelaire's flâneur (Benjamin, 1997). Quite simply, everyday life incivilities involving movement, bodily management and display, sounds and language respectively had roughly similar capacity to generate further relations and interactions (Kemper, 2002). Yet, when these four abstract categories are distilled into their component sub-types, distinct patterns start to emerge in the data. (A brief yet important point we make before moving on to these findings is that we designated 10 cases as the minimum number for a sub-type of incivility to warrant discussion and participation).

Moving first down column 1 in Table 5, incivilities where someone 'bumped into me' stood out for their heightened propensity to result in our respondents initially saying or 
Table 4. Progression rates: interactive episodes the recalled event passed through (and by implication respondent eligibility to complete corresponding module of questions) $(N=508)$

\begin{tabular}{|c|c|c|}
\hline & Percentage & $N$ \\
\hline \multicolumn{3}{|l|}{$\begin{array}{l}\text { Immediately before the event } \\
\text { Act } 1\end{array}$} \\
\hline $\begin{array}{l}\text { Immediately before the rude stranger came on the scene, where } \\
\text { were you and what were you doing? }\end{array}$ & 100 & 508 \\
\hline Act 2 & & \\
\hline $\begin{array}{l}\text { Entrance of the rude stranger on the stage: What were they } \\
\text { doing when you came across them? }\end{array}$ & 100 & 508 \\
\hline \multicolumn{3}{|l|}{ Events that 'started up' } \\
\hline $\begin{array}{l}\text { What did the stranger do in the very first instance that made you } \\
\text { think of them as rude? } \\
\text { Act } 4\end{array}$ & 100 & 508 \\
\hline How did you feel about what happened? & 100 & 508 \\
\hline \multicolumn{3}{|l|}{$\begin{array}{l}\text { Events with intermediate episodes } \\
\text { Act } 5\end{array}$} \\
\hline $\begin{array}{l}\text { Did you say or do anything back to them? } \\
\text { Act } 6\end{array}$ & 35.2 & 179 \\
\hline $\begin{array}{l}\text { Faced with what you did back to them, did the rude stranger } \\
\text { then go on to say or do anything in reply? } \\
\text { Act } 7\end{array}$ & 15.2 & 77 \\
\hline $\begin{array}{l}\text { Confronted with this response from the rude stranger, did you } \\
\text { take it further with them, by saying or doing something else? }\end{array}$ & 3.9 & 20 \\
\hline \multicolumn{3}{|l|}{$\begin{array}{l}\text { Events with big finales } \\
\text { Act } 8\end{array}$} \\
\hline $\begin{array}{l}\text { The final act: Now, how did the contact between yourself and } \\
\text { the rude stranger end up? Who ended up having the last word } \\
\text { (or action)? }\end{array}$ & 3.9 & 20 \\
\hline \multicolumn{3}{|l|}{$\begin{array}{l}\text { Immediately after the event } \\
\text { Act } 9\end{array}$} \\
\hline $\begin{array}{l}\text { Immediately after the rude stranger had gone, how did you feel } \\
\text { about what had happened? }\end{array}$ & 100 & 508 \\
\hline \multicolumn{3}{|l|}{$\begin{array}{l}\text { In the present (at the time of the telephone interview) } \\
\text { Act } 10\end{array}$} \\
\hline $\begin{array}{l}\text { How have you been feeling about the event since the time it } \\
\text { happened? }\end{array}$ & 100 & 508 \\
\hline
\end{tabular}

Source: ELIAS (2005).

doing something back to the rude stranger. Whereas about one in three of all incivilities nominated by our respondents moved into this initial reactive phase (35.2 per cent of total pool), the proportion for this kind of event was a little over one in two. Proceeding into column 2 , it can be seen that a much diminished number of events reached the next interactional stage with 'the rude stranger saying or doing something to me in reply'
(15.2 per cent of total pool). Yet certain initial incivilities seemed to experience lower attrition than others in making it to this stage. Invasions of personal space, problems of blocked motion, motor vehicle noises, unruly children, bad language and rude gestures were all prone to support sustained interactions.

We now turn to the last column of Table 5 which is based on the small subset of 20 incivil events recounted to us in the study 
Table 5. Interactive episodes the recalled event 'passed through', by types of everyday incivility $(N=508)$

\begin{tabular}{|c|c|c|c|c|}
\hline & $\begin{array}{l}\text { Act } 5 \\
\text { 'I said or did } \\
\text { something to } \\
\text { rude stranger' } \\
\text { (percentage) }\end{array}$ & $\begin{array}{l}\text { Act } 6 \\
\text { 'Rude stranger } \\
\text { said or did } \\
\text { something to } \\
\text { me in reply' } \\
\text { (percentage) }\end{array}$ & $\begin{array}{l}\text { Acts } 7 / 8 \\
\text { 'Myself and } \\
\text { rude stranger } \\
\text { continued to } \\
\text { have further } \\
\text { contact' } \\
\text { (percentage) }\end{array}$ & $N$ \\
\hline All reported incivilities & 35.2 & 15.2 & 3.9 & $(585)$ \\
\hline (1) Movement (aggregated) & 36.0 & 15.4 & 3.9 & $(358)$ \\
\hline (i) Bumped into me & 50.9 & 18.2 & 1.8 & $(55)$ \\
\hline (ii) Blocked my way & 41.1 & 17.9 & 10.7 & $(56)$ \\
\hline $\begin{array}{l}\text { (iii) Pushed in front of me } \\
\text { (cut me off) }\end{array}$ & 33.8 & 14.2 & 0.0 & (148) \\
\hline (iv) Tailed me & 19.0 & 9.5 & 0.0 & (21) \\
\hline $\begin{array}{l}\text { (v) Stopped abruptly in } \\
\text { front of me }\end{array}$ & 36.4 & 9.1 & 0.0 & (11) \\
\hline $\begin{array}{l}\text { (vi) Took up too much personal } \\
\text { space (seating) }\end{array}$ & 25.0 & 12.5 & 12.5 & (8) \\
\hline (vii) Invaded my personal space & 33.3 & 20.0 & 13.3 & (30) \\
\hline (viii) Swerved in front of me (child) & 31.8 & 18.2 & 4.5 & (22) \\
\hline $\begin{array}{l}\text { (ix) Sat or stood in front of me } \\
\text { (cinema) }\end{array}$ & 14.3 & 0.0 & 0.0 & (7) \\
\hline $\begin{array}{l}\text { (2) Bodily management and display } \\
\text { (aggregated) }\end{array}$ & 33.3 & 17.3 & 3.7 & $(81)$ \\
\hline (i) Spat & 0.0 & 0.0 & 0.0 & (2) \\
\hline $\begin{array}{l}\text { (ii) Bodily gesture (dirty or lewd } \\
\text { look, the ups) }\end{array}$ & 35.8 & 17.9 & 4.5 & $(67)$ \\
\hline $\begin{array}{l}\text { (iii) Waste disposal (fag end, } \\
\text { takeaway food packaging) }\end{array}$ & 50.0 & 25.0 & 0.0 & (4) \\
\hline $\begin{array}{l}\text { (iv) Acting in poor taste (reading } \\
\text { porn on train) }\end{array}$ & 12.5 & 12.5 & 0.0 & (8) \\
\hline (3) Sounds (aggregated) & 34.4 & 19.7 & 1.6 & (61) \\
\hline $\begin{array}{l}\text { (i) Mobile phone (loud ringing, } \\
\text { irritating ring tone) }\end{array}$ & 0.0 & 0.0 & 0.0 & (1) \\
\hline $\begin{array}{l}\text { (ii) Motor vehicle (beeping horn, } \\
\text { revving engine) }\end{array}$ & 36.8 & 26.3 & 5.3 & (19) \\
\hline (iii) Loud talking (in cinema) & 12.5 & 0.0 & 0.0 & $(8)$ \\
\hline $\begin{array}{l}\text { (iv) Screaming, screeching or } \\
\text { shouting(child) }\end{array}$ & 39.4 & 21.2 & 0.0 & (33) \\
\hline (4) Language (aggregated) & 34.1 & 18.1 & 3.5 & $(85)$ \\
\hline (i) Swearing & 34.8 & 19.7 & 4.5 & (66) \\
\hline (ii) Sexual remarks & 20.0 & 0.0 & 0.0 & (5) \\
\hline $\begin{array}{l}\text { (iii) Prejudicial comments (racist, } \\
\text { sexist) }\end{array}$ & 38.5 & 23.1 & 0.0 & (13) \\
\hline (iv) Non-English language & 0.0 & 0.0 & 0.0 & (1) \\
\hline
\end{tabular}

Source: ELIAS (2005).

(3.9 per cent of the 508 cases) where the respondent and the rude stranger continued to have further contact' above and beyond what had been played out up to Act 6. Here it is apparent that two sub-types of incivility stood out for their likelihood of reaching this more advanced stage of stranger-onstranger interaction, 'having my way blocked' 
(10.7 per cent) and the even more pronounced 'invading my personal space' (13.3 per cent). This finding once again serves to remind us of the importance of Goffman's (1971) analysis of individual movement in public places and the problem of maintaining orderly relations in public under the condition of embodied pedestrian stranger mobility.

\section{Incivility: Unpacking Patterns and Regularities within 'The City'}

The proposition that incivility is related to urban form prompted us to inquire how everyday life incivility is distributed within and beyond the city. Are the impacts upon the self different in the city and the country (Urry 1996)? Furthermore, does the seriousness of the incivil encounter vary over these boundaries? As we noted at the outset of this paper, deprived residential neighbourhoods close to the centres of major cities have been key sites for recent theory and analysis on the nature and form of incivility (Forrest and Kearns, 2001). Such work would lead us to paint a notably grim picture of the inner city as a zone of chaotic and threatening social life in comparison with leafy suburbs and picket-fence small towns. What do the ELIAS data have to say on these matters? Tables 6 and 7 bring the new data to bear on such questions and enable us comparatively to assess and specify the relative 'risks' of the urban environment. Taken as whole, they suggest that the inner city offers only a slightly increased probability of a negative encounter with a stranger.

The first part of Table 6 suggests that the inner city has no monopoly on rudeness. Some 15 per cent of our unpleasant interactions take place in the CBD and around a quarter in the inner suburbs. The rest take place elsewhere, some 27 per cent in outer suburbs and the remaining one-third in smaller regional cities, small towns and rural locations. Given the general feel of the sociological literature, this is quite a surprise. It is, however, consistent with our hypothesis that spatial zones and neighbourhoods explain less than is commonly believed and that we should switch our representation of the city to one inscribed by vectors and nodes. The remainder of Table 6 illuminates this theme. Locations associated with mass transport such as railway stations, bus stops and car parks are notably more risk-prone than consumption venues such as malls, clubs and pubs (see also Public Agenda, 2003). We can begin to see that movement 'through' places seems to have distinct effects in comparison with 'being in' a place (Kasinitz, 1994). It appears from 6.2 that 'getting somewhere' is more dangerous than 'being somewhere' and that what we might think of as the uninteresting, in-between spaces of daily life where people must pass but do not particularly wish to be or stay are less regulated and more risk-prone than their intended destinations. Our supposition is that the rush through such transitory locales increases the probability of a rude encounter. This contrasts with the consumption space, which perhaps encourages a more leisured form of movement that facilitates flâneurie. Note also from 6.2 that the traditional Goffmanian pavement was the setting for only 10 per cent of rude encounters (albeit almost double this quantity in the CBD), suggesting that the management of this setting is perhaps more effectively normatively regulated than those where human trajectories are multidirectional and chaotic, as epitomised by the Shinjuku railway station concourse in Tokyo.

Sub-section 6.3 seems to confirm this picture for the $\mathrm{CBD}$, where being on foot and public transport emerge as notable risk factors. Besides busy thoroughfares, the implicit image here is of crowded commuter trains and buses, jostling pedestrian crossings and the pressure to get to work on time. Yet, in residential zones, private vehicles become important as a predictor, reflecting the fact that the arduous and unpleasant task of 'getting somewhere' in such locations is less likely to be accomplished by the exposed body and that automotive solutions to the problem of speed and space have been built into the urban fabric. The final part of Table 6 shows a weak but interesting pattern. Section 6.4 suggests that being an 
Table 6. The distribution of everyday life incivility: movement and speed by location of event $(N=508)$

\begin{tabular}{|c|c|c|c|c|c|}
\hline & \multicolumn{3}{|c|}{ Percentage } & \multicolumn{2}{|c|}{$N$} \\
\hline \multicolumn{6}{|c|}{ (1) What was the general location where you came across the rude stranger? } \\
\hline Capital city: city centre & & \multicolumn{2}{|c|}{75} \\
\hline $\begin{array}{l}\text { Capital city: inner-city } \\
\text { suburbs }\end{array}$ & \multicolumn{3}{|c|}{25.4} & \multicolumn{2}{|c|}{129} \\
\hline $\begin{array}{l}\text { Capital city: outer-city } \\
\text { suburbs }\end{array}$ & \multicolumn{3}{|c|}{27.0} & \multicolumn{2}{|c|}{137} \\
\hline Regional city: city centre & \multicolumn{3}{|c|}{10.5} & \multicolumn{2}{|c|}{53} \\
\hline Regional city: suburbs & \multicolumn{3}{|c|}{11.4} & \multicolumn{2}{|c|}{58} \\
\hline Small town: town centre & \multicolumn{3}{|c|}{5.3} & \multicolumn{2}{|c|}{27} \\
\hline Small town: suburbs & \multicolumn{3}{|c|}{2.8} & \multicolumn{2}{|c|}{14} \\
\hline Rural or remote area & \multirow{2}{*}{\multicolumn{3}{|c|}{$\begin{array}{c}2.0 \\
100.0\end{array}$}} & \multirow{2}{*}{\multicolumn{2}{|c|}{$\begin{array}{c}14 \\
507^{\mathrm{a}}\end{array}$}} \\
\hline \multirow[t]{2}{*}{ Total } & & & & & \\
\hline & $\begin{array}{c}\text { All } \\
\text { events }\end{array}$ & $\begin{array}{l}\text { Big city: } \\
\text { centre }\end{array}$ & $\begin{array}{l}\text { Big city: } \\
\text { inner } \\
\text { suburbs }\end{array}$ & $\begin{array}{l}\text { Big city: } \\
\text { outer } \\
\text { suburbs }\end{array}$ & $\begin{array}{l}\text { Big city: } \\
\text { the } \\
\text { beyond }\end{array}$ \\
\hline \multicolumn{6}{|c|}{ (2) Where specifically were you? (percentages) } \\
\hline Shopping hub & 25.7 & 24.2 & 24.0 & 22.7 & 30.6 \\
\hline Leisure hub & 10.6 & 16.1 & 9.9 & 6.8 & 12.2 \\
\hline Mass transport hub & 53.6 & 40.3 & 57.0 & 59.8 & 50.3 \\
\hline Outdoors walkway & 10.2 & 19.4 & 9.1 & 10.6 & 6.8 \\
\hline Total & 100 & 100 & 100 & 100 & 100 \\
\hline$N$ & $463^{\mathrm{b}}$ & 62 & 121 & 132 & 147 \\
\hline$\chi^{2}$ & 16.5 & & & & \\
\hline p value & 0.057 & & & & \\
\hline \multicolumn{6}{|c|}{ (3) Were you on foot, in a vehicle, or on public transport? (percentages) } \\
\hline On foot & 56.9 & 73.3 & 49.2 & 49.6 & 62.8 \\
\hline In vehicle & 36.3 & 10.7 & 42.2 & 46.7 & 34.8 \\
\hline On public transport & 6.3 & 16.0 & 8.6 & 3.6 & 2.4 \\
\hline Total & 100.0 & 100.0 & 100.0 & 100.0 & 100.0 \\
\hline$N$ & $505^{\mathrm{c}}$ & 75 & 128 & 137 & 164 \\
\hline$\chi^{2}$ & 43.6 & & & & \\
\hline $\mathrm{p}$ value & 0.000 & & & & \\
\hline \multicolumn{6}{|c|}{ (4) How fast or slowly were you trying to go compared with everyone else? (percentages) } \\
\hline Faster & $10.2^{\circ}$ & 12.8 & 8.1 & 7.8 & 13.2 \\
\hline Around the same speed & 73.6 & 71.8 & 75.8 & 84.4 & 61.8 \\
\hline Slower & 16.1 & 15.4 & 16.1 & 7.8 & 25.0 \\
\hline Total & 100.0 & 100.0 & 100.0 & 100.0 & 100.0 \\
\hline$N$ & $254^{\mathrm{d}}$ & 39 & 62 & 77 & 76 \\
\hline & 11.4 & & & & \\
\hline $\mathrm{p}$ value & 0.078 & & & & \\
\hline
\end{tabular}

${ }^{\mathrm{a}} 1$ case with missing value.

$\mathrm{b}_{45}$ cases with missing value.

c 3 cases with missing value.

${ }^{d} 2$ cases with missing value, 252 cases excluded from analysis. (These cases did not exhibit the features of principal interest here, respondent 'moving' and people-in-general area 'moving'.)

Source: ELIAS (2005).

obstacle to the movement of others increases the risk of being a victim of incivility. It seems likely that those who are burdened are less nimble and will generate frustration in others. By contrast, those who are able to move faster are probably more agile and can slip through the crowd. They might generate incivil encounters in their haste, but they are 
more likely to think of themselves as agents than as 'victims'. This is bad news for those struggling around the city with push chairs, walking sticks or heavy baggage. It further suggests that there are currently expectations about the right to move at a 'reasonable' speed in public spaces and that sanctions can accumulate around those who might be thought to deny this 'right' to others. Of interest, we note that this pattern was at its strongest with respect to events outside the city limits, suggesting that norms for the city centre are more flexible than in areas where crowds and delays are not expected.

Table 7 concludes our schematic examination of these urban risk factors. We can see in 7.1 that residents of the big city (whether in the $\mathrm{CBD}$, inner suburbs or outer suburbs) were distinguished from non-residents by the slightly greater regularity with which they encountered rude strangers in their everyday lives. This finding is broadly consistent with that of Table 6.1, suggesting that the density of embodied movement interactions in the city increases the odds of an unpleasant encounter. Still, if a difference in exposure risks between the big city and the regions exists, it is nowhere near so great as we might suppose from the existing literature or from popular stereotypes. Table 7.2 explores whether simply spending a lot of personal time at familiar urban sites of mass cultural consumption such as food courts, department stores, multiplex cinema complexes, casinos, generic takeaway food chains, video/dvd rental stores, sports grounds and mass parking lots (see Baudrillard, 1998) augments the likelihood of encountering a rude stranger. The data suggest a modest tendency for these kinds of landscapes to generate rudeness in the inner suburbs of the big city. Yet, the overriding pattern was that, regardless of which of the four particular locations of interest are considered, being frequently present within such surroundings does not really matter that much for heightening one's risk of a distasteful encounter with a rude stranger. This result is consistent with that of Table 6.2 in suggesting that leisure zones confer immunity relative to transport nodes. They are probably better organised spatially, more closely regulated by identifiable staff and encourage transient subjectivities that are more relaxed and ludic, thus allowing potential incivilities to be laughed off or even perceived as appropriate to the setting.

Table 7.3 shows that the consequences of coming across a rude stranger in everyday life tend to vary with the location of the event. In particular, occurrences that take place in the centre of the city tend to be markedly different. They were much more prone than events that happened in the suburbs and provinces to be 'deep events' that resulted in follow-up relations and interactions between the respondent and the rude stranger in the aftermath of the initial infraction. This result was not only comparatively strong, but consistent across all of the three episodic stages. Perhaps the bustling city centre, by simultaneously providing anonymity and a public gallery of onlookers, encourages the individual righteously to turn off habitual controls over emotional restraint and to bring the rude stranger to account for their transgression against, and in front of, 'all of us' (Collins, 1988; Elias and Dunning, 1986; Noe, 2002; Smith, 1999; Zukin, 1993). It would be interesting to know what type of individual is altered in such ways upon encountering a rude stranger in the heart of the metropolis. We might anticipate that it would be unlikely to be Simmel's (1997; see also Bauman, 2003) blasé urban resident, the kind of person who exists in a self-protecting psychic cocoon of indifference to the shocks of urban life. By contrast, recent popular accounts have pointed to the protected suburbanite as being at a heightened risk, their self-control unravelling in the face of the rude stranger in the inner metropolis. Consider, for example, the 1990s Hollywood film Falling Down (Schumacher, 1993). Here, Michael Douglas's character 'D-Fens' illustrates a worst-case scenario of what could happen to such an Everyman when this prospect becomes a reality.

Although a specific answer to this question is beyond the mandate of the present article, Table 7.4 does provide some preliminary data. We asked our respondents whether 
Table 7. Cross-tabulations: unravelling the connections between everyday life incivility and the city $(N=508)$

\begin{tabular}{|c|c|c|c|c|c|}
\hline & All events & Big city: centre & $\begin{array}{l}\text { Big city: } \\
\text { inner } \\
\text { suburbs }\end{array}$ & $\begin{array}{l}\text { Big city: } \\
\text { outer } \\
\text { suburbs }\end{array}$ & $\begin{array}{l}\text { Big city } \\
\text { the } \\
\text { beyond }\end{array}$ \\
\hline \multicolumn{6}{|c|}{ (1) Regularity with which come into contact with rude strangers, by place of residence (percentages) } \\
\hline More than weekly & 41.5 & 43.7 & 48.4 & 43.9 & 33.5 \\
\hline Every few weeks or so & 32.6 & 31.0 & 31.0 & 29.5 & 37.2 \\
\hline Less than once a month & 25.9 & 25.4 & 20.6 & 26.5 & 29.3 \\
\hline Total & 100.0 & 100.0 & 100.0 & 100.0 & 100.0 \\
\hline$N_{2}$ & 494 & 71 & 126 & 132 & 164 \\
\hline$\chi^{2}$ & 7.9 & & & & \\
\hline $\mathrm{p}$ value & 0.244 & & & & \\
\hline \multicolumn{6}{|c|}{$\begin{array}{l}\text { (2) Regularity of presence in landscapes of mass culture consumption, by place of residence } \\
\text { (percentages) }\end{array}$} \\
\hline High presence & 31.0 & 31.9 & 35.2 & 32.4 & 25.9 \\
\hline Moderate presence & 35.2 & 38.9 & 32.8 & 37.5 & 33.7 \\
\hline Low presence & 33.8 & 29.2 & 32.0 & 30.1 & 40.4 \\
\hline Total & 100.0 & 100.0 & 100.0 & 100.0 & 100.0 \\
\hline$N$ & 503 & 72 & 128 & 136 & 166 \\
\hline$\chi^{2}$ & 6.2 & & & & \\
\hline $\mathrm{p}$ value & 0.399 & & & & \\
\hline \multicolumn{6}{|c|}{ (3) Interactive episodes the recalled event 'passed through', by place of residence (percentages) } \\
\hline $\begin{array}{l}\text { Act 5: 'I said or did } \\
\text { something to the rude } \\
\text { stranger' }\end{array}$ & 35.4 & 44.6 & 34.1 & 33.6 & 33.9 \\
\hline $\begin{array}{l}\text { Act 6: 'Rude stranger said or } \\
\text { did something to me in } \\
\text { reply' }\end{array}$ & 15.2 & 29.3 & 14.7 & 15.3 & 9.0 \\
\hline $\begin{array}{l}\text { Acts } 7 / 8 \text { : 'Myself and rude } \\
\text { stranger continued to } \\
\text { have further contact' }\end{array}$ & 3.9 & 9.3 & 2.3 & 2.2 & 4.2 \\
\hline$N$ & 507 & 75 & 129 & 137 & 166 \\
\hline \multicolumn{6}{|c|}{$\begin{array}{l}\text { (4) Orientation to 'people-in-general' in public places since most recent experience of everyday life } \\
\text { incivility, by place of residence (percentages) }\end{array}$} \\
\hline More tolerant (yes) & 38.0 & 38.7 & 39.5 & 38.7 & 36.1 \\
\hline More remonstrative (yes) & 25.2 & 22.7 & 24.0 & 25.5 & 27.1 \\
\hline More avoidant (yes) & 6.9 & 2.7 & 4.7 & 7.3 & 10.2 \\
\hline$N$ & 508 & 75 & 129 & 137 & 166 \\
\hline
\end{tabular}

Source: ELIAS (2005).

their orientation to 'people-in-general' in public places had changed since their latest encounter with the rude stranger. What these results show is that no matter where you reside, the extent to which you were now more tolerant, more remonstrative or more avoidant departed little from figures for the overall sample of respondents who had been out in public places since the event $(38.0$ per cent, 25.2 per cent and 6.9 per cent respectively). In short, the vision of thick-skinned, blasé urbanites and anxious, emotionally fragile suburbanites does not hold up well to scrutiny. We further note that the response of aversion and avoidance so beloved of contemporary urban criminology is not very common once respondents are provided with alternative response categories (most surveys simply ask about 'fear' with predictable results). Table 7.4 clearly shows that most people do not hide away terror-struck after meeting an unruly stranger. On the contrary, 
they are more likely to develop active strategies that will allow them better to manage such encounters in future, perhaps looking to temper their own prejudices and immediate impulses (tolerance) or being more ready than ever to stand up to defend the good and engage with the offender (remonstration).

\section{Discussion}

In conjunction with our prior focus group work, the results presented here provide the possibility for reimagining and opening up the study of incivility in society today. Politicians increasingly speak of the need for a culture of respect and decency, but point the finger only at 'yob culture'. Social science makes investigations of incivility that focus on the poorest parts of the city. The more general and impartial benchmarking activity that can contextualise such activity in its specificities has yet to be widely conducted. Our research has made a step in this direction by investigating incivility without pre-judging where the problem lies and by bringing into the research environment the neglected concept set of strangers, circulations and bodies. In our earlier work, we made a number of surprising discoveries (Phillips and Smith, 2003; Smith and Phillips, 2004). 'Respectable' people such as the middleaged and elderly were the most likely perpetrators of an everyday incivility, not minority youth; incivilities could take a variety of forms, but most involved the body or language; consumption spaces and transport nodes were the most likely venues for the incivil encounter and not the residential neighbourhood; fear and retreatism were not common responses to incivility. This paper has added to such focus group results in a small but still cumulative way. Moreover, because they are quantitative and derived from a systematic sampling frame they carry with them the reassuring advantages of triangulation. We have seen that only a few interpersonal encounters really escalate and that certain incivilities can drive escalation more than others; that the management of personal space and the body in a context of pedestrian movement is problematic; that there is surprisingly little difference between the incivility profiles and behavioural responses of urban, suburban and extra-urban dwellers; and we again confirmed that avoidance is an unusual rather than a modal response. We have further identified some risk factors. Transport nodes and vectors now appear more risky than consumption venues. The odds of a more serious rude encounter are greatest for those who live in a large city, who travel frequently on foot through transport nodes and who move more slowly than those around them. In this situation, where everyone is trying to get somewhere else they would rather be, our victim is most likely to encounter an embodied challenge or insult, to be pushed, to be blocked or to have their personal space invaded in some way. Such findings throw down a gauntlet to established research interests and protocols. The overall picture of the experience of incivility that is developing from our work is one of far greater complexity and variety than we might imagine after a tour through the criminological literature of blighted neighbourhoods replete with graffiti, vacant lots, burnt-out cars and home boys who produce only the flight of those fearful respectable citizens. Our image is of movement. It is of people bumping into each other on a station concourse, pushing into queues at the ATM, using bad language on the train and sometimes demanding an apology. The door is only just starting to open for a more comprehensive and less stereotyped investigative agenda.

We can most usefully conclude by noticing that the 'broken windows' archetype is concerned with observed rather than experienced incivilities. That approach takes the city as a text and the citizen as a reader. In many ways, this is the perspective of the academic outsider looking in on human activity. Our results suggest that a more naturalistic approach is needed, one that understands an embodied and moving subjectivity as central to the dynamics of incivility today and that makes space for folk-definitions of what is 'incivil' or rude, one that looks at 
situations and not postcodes. Despite their absence from the standard protocols of criminological incivility research with its obsession with the grimy 'block' and dubious 'neighbourhood', it will be recalled that invasions of personal space, impeded motion, pushing and shoving and so forth accounted for around 60 per cent of our reported events. This finding makes Goffman's work seem particularly prescient given the importance he attributed to the sacred character of self (Lyman, 1973). Under this cultural attribute of modernity, the right of the individual to move at any chosen time through public space at a speed and in a direction of their own determination and surrounded by a protective bubble of air becomes heightened (Bauman, 2000). With this comes the expectation and hope that there will be shared and enforced norms about appropriate modes of movement, queuing and interpersonal distance. It is the felt emotional consequences of having one's movement through a public place impeded or encroached upon that is an important generator of incivil encounters precisely because the sacred status of the self is threatened (Elias, 1994). Human circulations in cities are increasing. Accidents, collisions and invasions are not only inevitable but they are also likely to multiply in coming years in the dense and often only loosely regulated spaces of urban life (Bauman, 2000; Virilio, 1986). Theorising the relationship between flows, circulations and disorder would seem to be a major task for future incivility research. This would not preclude an applied or policy-relevant focus looking at ways to make transport nodes and mass transit less risk-prone. One imagines that simple structural reforms such as wider walkways and doors, free baggage trolleys and better lines of sight could help. Retail-driven innovations such as plantings and lighting could also improve the ambience of such locations, subtly changing the mood away from that of insistent urgency rather than simply signalling safety. A simple comparative study of Waterloo Station and one of the better airports or even a crowded theme park might provide a few clues.
This said, whether the circumstance of a likely increase in interpersonal incivility is something that we should really be worried about or spend a lot of money on is open to debate. Our data suggest that the unruly stranger is less of a problem than we might suppose. If the words of politicians, the culture-diagnoses of Bauman and the presuppositions of criminologists and urban planners are taken seriously, then an allegedly rampant incivility contributes in a dangerous and corrosive way to the collapse of the social and the end of a true public sphere in our cities and towns. Yet we found that only a third of all our respondents had encountered an unruly stranger in the prior month. On average, we might each expect very few such encounters every year-perhaps three or four or five, but sometimes none. Moreover, the allegedly fragile CBD and inner-city suburbs seemed to be only slightly more 'at risk' from the rude stranger than rural parts. They do not appear to be a spatial zone worthy of the near-exclusive attention they have received in the academic literature. The scattered events that take place there might even be beneficial, if we keep faith with Durkheim's (1974) claim that deviance might have a plus side. Is it not a good thing that around a third of incivil prompts led to norm-reinforcing responses such as asking for an apology or otherwise indicating that an infraction had taken place; that only 1 in 25 rumbled on to escalate; that the personal intent to become more tolerant in future far outnumbered the response of aversion and retreat? It would seem that civility is still being defended and the possibility remains for a civil society in a context of urban anonymity.

\section{Notes}

1. Ralph Taylor (2000) provides an excellent critical review of the literature. It is instructive to contrast his systematic overview with the brief one we provide here. Readers will see that Taylor's position is that of a critic within the dominant discourse who seeks methodological refinement and conceptual clarity. In this respect, he is representative 
of the intellectual spirit of the field as a whole. Likewise, a review of the neighbourhood effects literature by Sampson et al. (2002) works with the idea that we need better ways to conceptualise and measure the neighbourhood, not that we need to imagine and model the city in new ways. Our position is that a more extensive rethinking is required.

2. This observation holds even for the best data we have. The well-known Baltimore dataset, for example, had assessments of over 800 street blocks, but the incivility variables are 'vandalism', 'rowdy teens' and 'abandoned building'. This approach does not come close to capturing the subtleties of rude or unpleasant behaviour in the city.

3. It should be noted that our methodology also drove us to situate these event sequences within the wider time-frame outside the interaction setting. We did this by asking all 508 respondents what 'was happening' immediately before the incivil event (Acts 1 and 2), what emotions they experienced straight after the rude stranger was gone (Act 9) and how they had been feeling and responding to the event in the following days and weeks (Act 10). For reasons of space, we cannot go into these results here.

\section{References}

abs (Australian Bureau of Statistics) (2002) 2001 Census of Population and Housing for Australia: Selected Social and Housing Characteristics. 2015.0. Canberra: ABS.

ACMA (Australian Communications AND Media Authority) (2005) Strong growth in broadband and mobile services in 2004-05, while fixed services decline. Media Release 60, 7 December.

Ballard, J. G. (2001) Super-Cannes. London: Flamingo.

BAteson, G. (1973) Steps to an Ecology of Mind. St Albans: Paladin.

BAUdrillard, J. (1998) America. London: Verso.

Bauman, Z. (2000) Liquid Modernity. Cambridge: Polity Press.

Bauman, Z. (2003) Liquid Love. Cambridge: Polity.

Bauman, Z. (2005) Liquid Life. Cambridge: Polity.

Benjamin, W. (1997) Charles Baudelaire. London: Verso.

CAntor, D. and Lynch, J. P. (2000) Self-report surveys as measures of crime and criminal victimization, Measurement and Analysis of Crime and Justice, Criminal Justice 2000, Vol 4, pp. $85-138$.
Carlyle, T. (1855/2003) Critical and Miscellaneous Essays. Kila, MT: Kessinger.

Collins, R. (1988) Theoretical Sociology. San Diego, CA: Harcourt Brace Jovanovich.

Collins, R. (2000) Situational stratification, Sociological Theory, 18(1), pp. 17-43.

DAvis, P. W. (1991) Stranger intervention into child punishment in public places, Social Problems, 38, pp. 227-246.

Duncan, M. G. (1996) Romantic Outlaws, Beloved Prisons: The Unconscious Meanings of Crime and Punishment. London: New York University Press.

Durkheim, E. (1974) The Division of Labour in Society. New York: Free Press.

Elias, N. (1987) Involvement and Detachment. Oxford: Blackwell.

Elias, N. (1994) The Civilizing Process. Oxford: Blackwell.

Elias, N. and Dunning, E. (1986) Quest for Excitement. Oxford: Blackwell.

Ellis, B. E. (2005) Lunar Park. London: Picador.

Emmison, M. and Smith, P. (2000) Researching the Visual: Images, Objects, Contexts and Interactions in Social and Cultural Inquiry. London: Sage.

Fine, G. A. and Smith, G. W. H. (2000) Erving Goffman Four-Volume Set. London: Sage.

FISCHER, C. (1999) Uncommon values, diversity, and conflict in city life, in: N. SMELSER and J. Alexander (Eds) Diversity and its Discontents, pp. 213-227. Princeton, NJ: Princeton University Press.

Forrest, R. and Kearns, A. (2001) Social cohesion, social capital and the neighbourhood, Urban Studies, 38(12), pp. 2125-2143.

Goffman, E. (1971) Relations in Public. London: Allen Lane.

Hall, S. and Gieben, B. (Eds) (1992) Formations of Modernity. Cambridge: Polity.

Ives, D. (1995) All in the Timing. London: Vintage.

JACOBS, J. (1961) The Death and Life of Great American Cities. New York: Random House.

Kasinitz, P. (Ed.) (1994) Metropolis: Centre and Symbol of Our Times. New York: Palgrave Macmillan.

Kemper, T. (2002) Predicting emotions in groups, in: J. BARbalet (Ed.) Emotions and Sociology, pp. 53-68. Malden, MA: Oxford.

LEWIS, D. A. and MAXFIELD, M. G. (1980) Fear in the neighborhoods: an investigation of the impact of crime, Journal of Research in Crime and Delinquency, 17, pp. 160-189.

LymAn, S. (1973) Civilization: contents, discontents, malcontents, Contemporary Sociology, 2, pp. 360-366.

NoE, G. (Dir.) (2002) Irreversible. Lion's Gate Films. 
Perkins, D. D., Meeks, J. W. and Taylor, R. B. (1992) The physical environment of street blocks and resident perceptions of crime and disorder: implications for theory and measurement, Journal of Environmental Psychology, 12, pp. 21-34.

Phillips, T. (2006) Uncivil relations with strangers: how individual people reflect on a commonplace experience in everyday life, Australian Journal of Social Issues, 41 (forthcoming).

Phillips, T. and Smith, P. (2003) Everyday incivility: towards a benchmark, The Sociological Review, 51(1), pp. 85-108.

Phillips, T. and Smith, P. (2005) ElIAS: Everyday Life Incivilities: An Australian Study. Launceston, Tasmania: University of Tasmania and New Haven, CT: Yale University.

Public Agenda (2003) Push comes to shove: passengers and travel workers call rudeness a problem. Press Release, 17 December (http:// www.publicagenda.org/press/press_release detail.cfm?list=56 (accessed 9 December 2005).

Reggio, G. (Dir.) (1983) Koyaanisqatsi. IRE Production.

Richardson, P. and Weill, P. (1999) Telstra's national telemarketing centre, Journal of Information Technology, 14(3), pp. 217-234.

Robinson, J. B., LAwton, B. A., TAylor, R. B. and PERKINS, D. D. (2003) Multilevel longitudinal impacts of incivilities: fear of crime, expected safety and block satisfaction, Journal of Quantitative Criminology, 19(3), pp. 237-274.

Rountree, P. and LAnd, K. (1996) Perceived risk versus fear of crime: empirical evidence of conceptually distinct reactions in survey data, Social Forces, 74, pp. 1353-1376.

Sampson, R. and Raudenbush, S. W. (1999) Systematic social observation of public spaces: a new look at disorder in urban neighbourhoods, American Journal of Sociology, 105(3), pp. 603-651.

Sampson, R., Morenoff, J. D. and GannonRowley, T. (2002) Assessing neighbourhood effects: social processes and new directions in research, Annual Review of Sociology, 28, pp. 443-478.
Schumacher, J. (Dir.) (1993) Falling Down. Warner Bros.

Sennett, R. (1994) Flesh and Stone: The Body and the City in Western Civilization. New York: Norton.

Simmel, G. (1997) The metropolis and mental life, in: D. Frisby and M. FEATherstone (Eds) Simmel on Culture, pp. 174-185. London: Sage.

Skogan, W. (1990) Disorder and Decline: Crime and the Spiral of Decay in American Cities. New York: Free Press.

SMITH, P. (1999) The elementary forms of place and their transformations: a Durkheimian model, Qualitative Sociology, 22(1), pp. 13-36.

Smith, P. and Phillips, T. (2004) Emotional and behavioral responses to everyday incivility: challenging the fear/avoidance paradigm, Journal of Sociology, 40(4), pp. 378-399.

TAYlOR, R. D. (2000) The incivilities thesis: theory, measurement, and policy, in: R. H. LANGWORThy (Ed.) Measuring What Matters, pp. 65-87. Washington, DC: National Institute of Justice/Office of Community Oriented Policing Services.

URRY, J. (1996) Sociology of time and space, in: B. S. Turner (Ed.) The Blackwell Companion to Social Theory, pp. 369-395. Oxford: Blackwell.

Virilio, P. (1986) Speed and Politics: An Essay on Dromology. New York: Columbia University Press.

Weisberg, H. F., Krosnick, J. A. and Bowen, B. D. (1996) An Introduction to Survey Research, Polling, and Data Analysis, 3rd edn. London: Sage.

Wilson, J. Q. (1975) Thinking About Crime. New York: Basic Books.

Wilson, J. Q. and Kelling, G. (1982) Broken windows, Atlantic Monthly, 211, pp. 29-38.

Zedner, L. (2002) Victims, in: M. Maguire, R. Morgan and R. REIner (Eds) The Oxford Handbook of Criminology, 3rd edn, pp. 419-456. New York: Oxford.

ZuKIN, S. (1993) Landscapes of Power: from Detroit to Disney World. Berkeley, CA: University of California Press. 